\title{
Acid Phosphatase Activity in the Wild-type and $B$-mutant Hyphae of Schizophyllum commune
}

\author{
By MARJATTA RAUDASKOSKI \\ Department of Botany, Institute of Biology, University of Turku, \\ 20500 Turku 50, Finland
}

(Received 26 November 1975; revised I 2 January 1976)

\section{SUMMARY}

In the wild-type and B-mutant hyphae of Schizophyllum commune, acid phosphatase activity was found in association with vacuoles, lipid bodies, and endoplasmic reticulum. Small granules containing acid phosphatase also occurred in mitochondria and along the nuclear envelope. Both ultrastructural and biochemical studies indicated greater acid phosphatase activity in the $B$-mutant than in the wild-type hyphae, which suggests that the mutation in the $B$ incompatibility factor increases the production of the acid phosphatase in the mutant hyphae.

\section{INTRODUCTION}

In the basidiomycete Schizophyllum commune, mating competence and sexual morphogenesis are determined and controlled by a bifactorial incompatibility system, comprising two series of factors, $A$ and $B$ (Raper, I966). Fertile dikaryons are established by compatible matings between homokaryons having different $A$ and different $B$ factors. Matings between homokaryons with common $A$ or common $B$ factors result in the establishment of common$A$ or common- $B$ heterokaryons with specific morphologies. Homokaryotic strains with a mutation in the $B$ factor mimic the heterokaryon formed by two homokaryons with the same $A$ but different $B$ factors (Parag, 1962), and are characterized by the breakdown of the septa and continuous nuclear migration from cell to cell (Koltin \& Flexer, 1969). An ultrastructural study of the $B$-mutant hyphae showed an abundance of vacuoles in the hyphal cells. Raudaskoski \& Koltin (1973) suggested that these vacuoles resulted from the operation of the $B$ factor in the mutant hyphae and that they contained hydrolytic enzymes. In the present study, acid phosphatase (EC. 3.I.3.2) was chosen as a representative of the hydrolytic enzymes and was localized at the ultrastructural level in the $B$-mutant and wildtype hyphae. The acid phosphatase activity was also determined biochemically from crude cell-free extracts of both types of hyphae.

\section{METHODS}

Mating of strains. Two types of dikaryons were formed by the method of Koltin \& Flexer (1969) and Raudaskoski \& Koltin (1973). One of the dikaryons was formed between two strains each carrying the same mutant $B$ factor (Parag, 1962) but different $A$ factors $(A I$ and $A 2$ ). The other dikaryon was formed by mating two wild-type strains with the factors $A 43 B 43$ and $A 26 B 26$. Both dikaryons produced fruiting-bodies, from which spores were isolated and grown to give monosporous homokaryotic cultures. 
Preparation of hyphae for electron microscopy. Acid phosphatase activity was localized in mutant and wild-type homokaryotic hyphae grown from monosporous cultures for $96 \mathrm{~h}$ on complete medium (Snider \& Raper, 1958). The hyphae were fixed in $3 \%$ (v/v) glutaraldehyde in $0.05 \mathrm{M}$-sodium acetate buffer $\mathrm{pH} \mathrm{6.9}$, washed for $3 \mathrm{~h}$ in a series of $0.05 \mathrm{M}$-acetate buffers of decreasing $\mathrm{pH}(6.9,6.0,5.5$, and 5.0$)$, and incubated for $30 \mathrm{~min}$ in Gomori medium at $37{ }^{\circ} \mathrm{C}$ (Gomori, 1952; Berjak, 1972). After incubation, the hyphae were washed for $\mathrm{I} \mathrm{h}$ in a series of acetate buffers of increasing $\mathrm{pH}$, up to 6.9. Post-fixation was carried out for $2 \mathrm{~h}$ in $\mathrm{I}:(\mathrm{w} / \mathrm{v})$ osmium tetroxide. Some of the hyphae were not post-fixed, to reveal the effect of osmium tetroxide on the incubated material. Control media were prepared either by adding to the incubation medium $0.03 \mathrm{M}$-sodium fluoride which inhibits acid phosphatase activity, or by omitting the substrate sodium- $\beta$-glycerophosphate from the medium. After post-fixation, the material was dehydrated in an ethanol-propylene oxide series, and embedded in Epon (Raudaskoski, 1970). Some of the mutant and wildtype homokaryotic hyphae were prepared without incubation in Gomori medium. The incubated material was not post-stained. All sections were examined in an AEI EM6B electron microscope.

Preparation of cell-free extracts and measurement of enzyme activity. Mutant and wildtype homokaryotic hyphae grown for 96 or $124 \mathrm{~h}$ were collected in 2 to $3 \mathrm{ml} \mathrm{O} \cdot \mathrm{I} \mathrm{M}$-Tris$\mathrm{HCl}$ buffer $\mathrm{pH} 7 \cdot 6$. Cell-free extracts were prepared by grinding the hyphae with acidwashed sand for $20 \mathrm{~min}$ and then centrifuging, first at $9750 \mathrm{~g}$ for $30 \mathrm{~min}$ in a Sorvall SS- 1 centrifuge, and then for $\mathrm{I} h$ at $16000 \mathrm{~g}$ in an MSE TC centrifuge. The cell-free extracts were maintained at a temperature below $4{ }^{\circ} \mathrm{C}$. The reaction mixture for the assay of acid phosphatase activity contained: $2 \mathrm{ml} 0.15 \mathrm{M}$-sodium acetate buffer $\mathrm{pH} 5.0,0.5 \mathrm{ml} 3.65 \mathrm{mM}$ $o$-carboxyphenyl phosphate (Worthington) as the substrate, and $0.5 \mathrm{ml}$ of cell-free extract in various dilutions (Brandenberger \& Hanson, 1953; Hofstee, 1954). The initial rate of hydrolysis of $o$-carboxyphenyl phosphate was determined by following the increase in absorption at $300 \mathrm{~nm}$ caused by liberation of salicylic acid, using a Perkin-Elmer 402 ultraviolet-visible spectrophotometer. One enzyme unit is equivalent to I $\mu$ mol $o$-carboxyphenyl phosphate hydrolysed per minute under the specified conditions at $25^{\circ} \mathrm{C}$. Protein was estimated by the method of Lowry et al. (I95I) and the activity of the acid phosphatase was calculated as mu. (mg protein $)^{-1}$.

\section{RESULTS}

\section{Electron microscopy}

The wild-type hyphae had undissolved septa, cytoplasm that was tightly packed with ribosomes, multivesicular bodies, and vacuoles that were sometimes filled with unidentified granular material (Fig. 1). In these hyphae, the reaction product of acid phosphatase activity was deposited around some vacuoles (Fig. 2), and lead phosphate was also deposited inside the vacuoles (Fig. 3). There were abundant deposits of reaction product in the electronopaque bodies typical of the wild-type hyphae; these are thought to contain lipids in view of their reaction with osmium tetroxide (Fig. 4). Acid phosphatase-positive granules also occurred along the endoplasmic reticulum (Fig. 4), and a small number of granules were observed in mitochondria (Fig. 3), along the nuclear envelope, and occasionally in the cytoplasm (Fig. 5).

The $B$-mutant hyphae had dissolved septa, a plasma-membrane that was often withdrawn from the cell wall, cytoplasm that was loosely packed with ribosomes, multivesicular structures smaller than in the wild-type hyphae, and many vacuoles, containing some electron- 

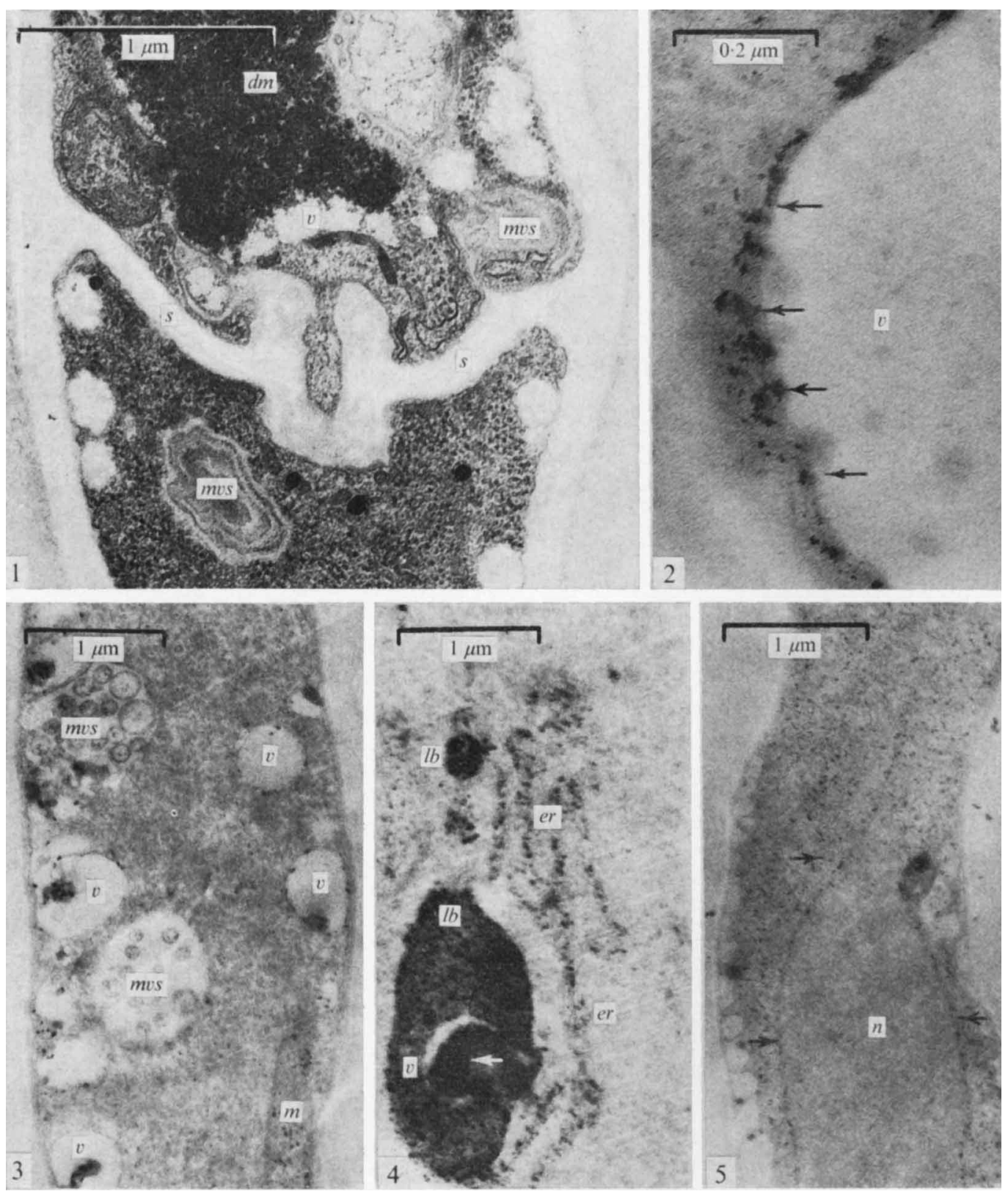

Fig. I. An untreated wild-type hypha with septum (s), vacuole (v), and multivesicular structures (mvs). In the upper cell there is a vacuole filled with electron-opaque material $(\mathrm{dm})$.

Fig. 2. A vacuole ( $v$ ) of a wild-type hypha incubated in Gomori medium. Reaction products (arrowed) occur in the cytoplasm close to the vacuolar membrane.

Fig. 3. Small granules of the reaction product in the cytoplasm, in vacuoles ( $v$ ), and in a mitochondrion $(m)$ of a wild-type hypha. $m v s$, Multivesicular structures.

Fig. 4. Acid phosphatase-positive granules in lipid bodies $(l b)$, and along endoplasmic reticulum (er) in a wild-type hypha. The arrow points to a heavy concentration of granules partially surrounded by a vacuole $(v)$ in the larger lipid body.

Fig. 5. Small granules in the cytoplasm and along the nuclear envelope $(n)$ (arrowed) in a wildtype hypha. 

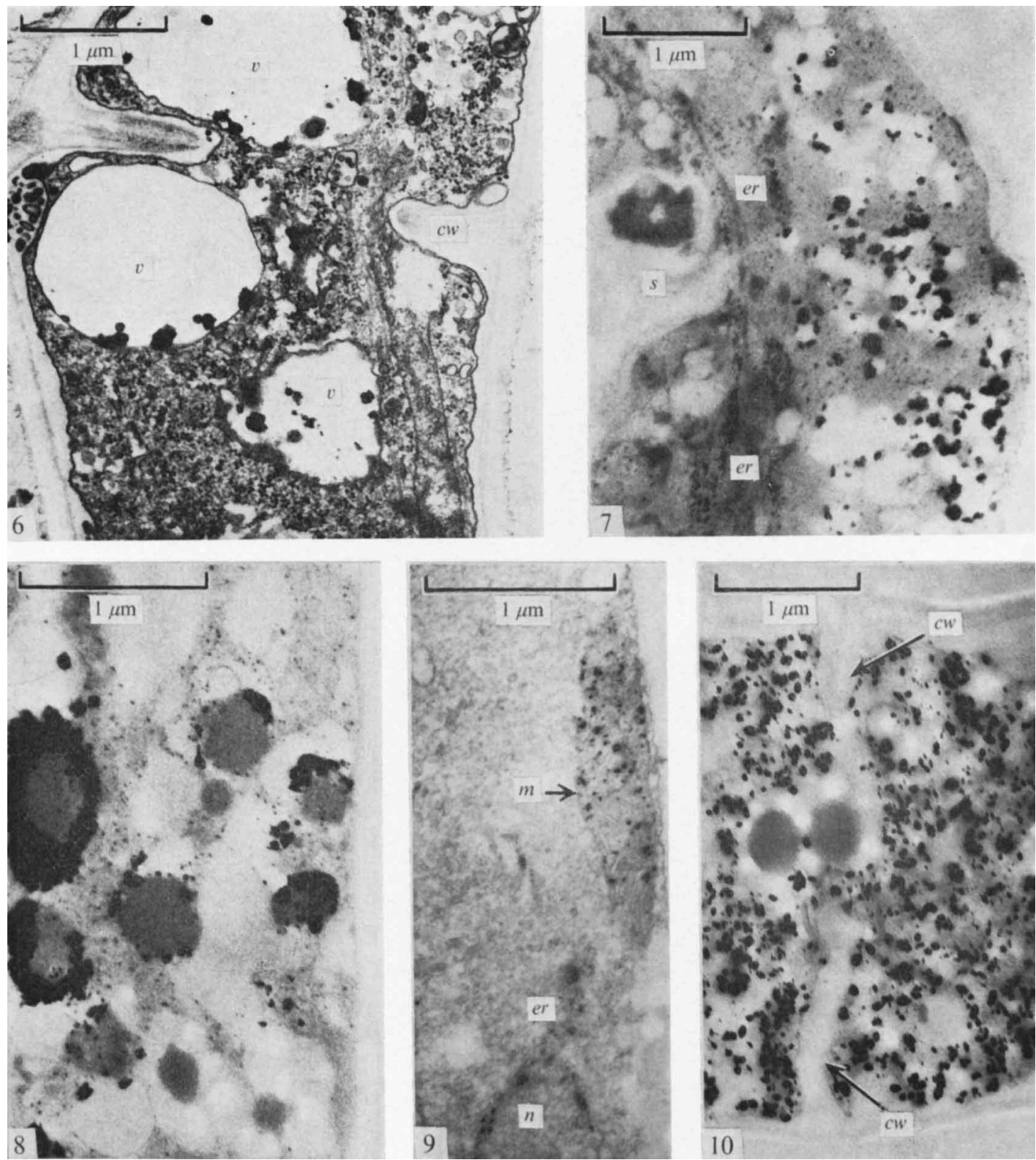

Fig. 6. An untreated $B$-mutant hypha with dissolved septum, and large vacuoles (v) with some electron-opaque material. $c w^{\prime}$, Cross wall of the septum.

Fig. 7. A $B$-mutant hypha with a dissolved septum (s), and abundant reaction product associated with vacuoles and endoplasmic reticulum (er).

Fig. 8. Acid phosphatase activity around lipid bodies in a $B$-mutant hypha.

Fig. 9. A $B$-mutant hypha showing acid phosphatase-positive granules at the nuclear envelope $(n)$, along the endoplasmic reticulum $(e r)$ and in a mitochondrion $(m)$.

Fig. IO. A heavy precipitation of acid phosphatase-positive granules in a $B$-mutant hypha. $c w$, Cross wall. 
Table I. The specific activity of acid phosphatase in the wild-type and B-mutant homokaryons of Schizophyllum commune

$\begin{array}{ccc}\text { Growth time (h) } & \overbrace{\text { Wild type }} & \begin{array}{c}\text { B mutant } \\ \text { [mu. (mg protein) }\end{array} \\ 96 & 11 \cdot 5 & 79 \cdot 8 \\ 124 & 36.5 & 82.9\end{array}$

opaque material (Fig. 6). In the $B$-mutant hyphae, the deposition of the reaction product of acid phosphatase activity occurred at the same sites as in the wild-type hyphae, although the overall deposition was much greater (Fig. 7). Acid phosphatase activity was more frequently observed inside the vacuoles in the mutant than in the wild-type hyphae. The lipid bodies of the mutant hyphae were smaller than those in the wild-type but their acid phosphatase activity was greater (Fig. 8). Stained granules were also observed in the mutant hyphae along the endoplasmic reticulum (Figs. 7 and 9), at the nuclear envelope, and in mitochondria (Fig. 9). In $B$-mutant hyphae, there was sometimes evidence of a strong acid phosphatase reaction in one of two adjacent cells, while in the other, there was either no reaction product, or it had a normal distribution. In a few mutant hyphae, all the cells contained large amounts of granules with acid phosphatase activity (Fig. I0). Activity was never observed to be distributed in these ways in the wild-type hyphae, and the presence of reaction product throughout the cytoplasm probably reflected the autolysis of the hypha.

No reactions comparable to those described above were observed in hyphae that had not been incubated in Gomori medium. Slight precipitation of lead phosphate was sometimes seen in the control hyphae incubated in the presence of $0.03 \mathrm{M}$-sodium fluoride or in the absence of substrate. No differences in the distribution of acid phosphatase activity were observed between post-fixed hyphae and those that were not post-fixed.

\section{Acid phosphatase activity in the cell-free extracts}

Two samples of wild-type and $B$-mutant hyphae were assayed for acid phosphatase activity. Owing to the slow growth of the hyphae carrying the mutant $B$ factor and the large amount of hyphae needed, the second samples of the wild-type and mutant hyphae were grown for $124 \mathrm{~h}$ instead of the $96 \mathrm{~h}$ period used for the electron microscopic studies and the first assay (Table I). The acid phosphatase activity was higher in both extracts from the mutant hyphae than in those from the wild-type hyphae; and the difference in activities was greater in the $96 \mathrm{~h}$ samples than in the $\mathrm{I} 24 \mathrm{~h}$ samples. In the wild-type hyphae a noticeable increase in acid phosphatase activity accompanied the growth of the hyphae, while in the $B$-mutant hyphae, the level of acid phosphatase activity was almost unchanged during growth from 96 to $124 \mathrm{~h}$.

\section{DISCUSSION}

Light-microscopic studies have shown that fungal hyphae possess particles with acid phosphatase activity (Pitt, 1968; Pitt \& Walker, 1967; Wilson, Stiers \& Smith, 1970; Reiss, 1972; Nehemiah, 1973), but there are very few cases in which acid phosphatase activity has been localized in fungi at the ultrastructural level (Wilson et al., 1970; Hislop et al., 1974; Scannerini et al., 1974). In this study of the hyphae of S. commune, acid phosphatase activity was observed in association with several different cell structures. It occurred 
at vacuoles, a site where acid phosphatase activity has also previously been localized in green plants (Halperin, 1969; Matile, 1969, 1975; Berjak, 1972) and in the fungi, Neurospora crassa (Zalokar, 1960; Matile, 1971), Coprinus lagopus (Iten \& Matile, 1970) and Sclerotinia fructigena (Hislop et al., 1974). The lipid bodies in the hyphae of $S$. commune showed strong acid phosphatase activity, but were different in appearance from the spherosomes which are involved in the lipid metabolism of green plants (Matile, 1975) and in which acid phosphatase activity has been demonstrated (Holocomb, Hildebrandt \& Evert, 1967; Halperin, 1969; Matile, 1969, 1975). Acid phosphatase activity was also shown by small granules in association with endoplasmic reticulum and in the cytoplasm of the hyphae of $S$. commune, and these might be part of the synthetic and storage mechanisms for the enzyme (Matile, 1975). The observation of some reaction product in mitochondria and along the nuclear envelope in the hyphae with normal cytoplasmic organization is in agreement with previous results. Zalokar (1960) found clear acid phosphatase activity in the mitochondrial fraction and weak activity in the nuclear fraction of Neurospora hyphae.

Both repressible and constitutive non-specific acid phosphatase are known in fungi, and it has been suggested that they have a nutritional role (Kuo \& Blumenthal, I96I; Dorn \& Rivera, 1966; Nyc, 1967; North \& Lewis, 197I). Acid phosphatase activity has also been demonstrated in fungi during intracellular lytic processes such as the release of ascospores from asci (Wilson et al., 1970), in the basidia (Nehemiah, 1973), and during the autolysis of fruiting bodies (Iten \& Matile, I970). In the present study, the biochemical technique measured the activity of non-specific acid phosphomonoesterases in a cell-free extract, using o-carboxyphenylphosphate as substrate (Brandenberger \& Hanson, 1953; Hofstee, 1954), while the electron-microscopic technique demonstrated $\beta$-glycerophosphatase activity in fixed cells (Gomori, 1952). The latter technique has been widely used to show lytic activity in both animal and plant cells. Although the substrate used in the biochemical technique was different from that in the electron-microscopic technique, it seems likely that the biochemical assay revealed the acid phosphatase activity involved in lytic processes as well as that connected with nutrition, since, in green plants, at least, it has been shown that the acid phosphatase activity of lytic processes is often substrate non-specific (Matile, 1975).

Although not directly comparable, both the biochemical and electron-microscopic results indicated higher acid phosphatase activity in the $B$-mutant than in the wild-type hyphae. No major difference was observed in the acid phosphatase activity between wildtype homokaryons and morphological mutants of $S$. commune in a biochemical study by Wilson (I972). The morphology of the hyphae of these mutants was, however, completely different from that of the $B$-mutant hyphae. Previous biochemical studies have shown that the appearance of the typical morphology of the $B$-mutant hyphae is associated with a decrease in R-glucan in the hyphal walls and a parallel increase in the activity of R-glucanase (Wessels, 1969). The increased activity of acid phosphatase observed in the $B$-mutant hyphae in this study suggests that a mutation in the $B$ incompatibility factor also increases the production of acid phosphatase in the hyphae. The increased acid phosphatase activity probably accelerates the lytic processes in the $B$-mutant hyphae, and thus contributes to their aberrant morphology. 


\section{REFERENCES}

BERJAK, P. (1972). Lysosomal compartmentation: ultrastructural aspects of the origin, development, and function of vacuoles in root cells of Lepidium sativum. Annals of Botany 36, 73-81.

BRANDENBERGER, H. \& HaNson, R. (1953). Spectrophotometric determination of acid and alkaline phosphatases. Helvetica chimica acta 36, 900-906.

DORN, G. \& RIVERA, W. (1966). Kinetics of fungal growth and phosphatase production in Aspergillus nidulans. Journal of Bacteriology 92, 1618-1622.

Gomori, G. (1952). Microscopic Histochemistry-Principles and Practice. Chicago: University of Chicago Press.

HALPERIN, W. (1969). Ultrastructural localization of acid phosphatase in cultured cells of Daucus carota. Planta 88, 91-I02.

Hislop, E. C., BARnaby, V. M., Shellis, C. \& LABorda, F. (I974). Localization of $\alpha$-L-arabinofuranosidase and acid phosphatase in mycelium of Sclerotinia fructigena. Journal of General Microbiology 8r, 79-99.

HoFsTEE, B. H. J. (I954). Direct and continuous spectrophotometric assay of phosphomonoesterases. Archives of Biochemistry and Biophysics 51, 139-146.

Holocomb, G. E., Hildebrandt, A. C. \& EVERT, R. F. (1967). Staining and acid phosphatase reactions of spherosomes in plant tissue culture cells. American Journal of Botany 54, 1204-1 209.

ITEN, W. \& MATILE, Ph. (1970). Role of chitinase and other lysosomal enzymes of Coprinus lagopus in the autolysis of fruiting bodies. Journal of General Microbiology 6r, 301-309.

Koltin, Y. \& FleXeR, A. S. (1969). Alteration of nuclear distribution in B-mutant strains of Schizophyllum commune. Journal of Cell Science 4, 739-749.

Kuo, M. H. \& Blumenthal, H. J. (I96I). Purification and properties of an acid phosphomonoesterase from Neurospora crassa. Biochimica et biophysica acta 52, $13-29$.

Lowry, O. H., Rosebrough, N. J., FARR, A. L. \& Randall, R. J. (195I). Protein measurement with the Folin phenol reagent. Journal of Biological Chemistry 193, 265-275.

Matile, Ph. (1969). Plant lysosomes. In Lysosomes in Biology and Pathology, pp. 406-430. Edited by J. T. Dingle and H. B. Fell. Amsterdam: North Holland.

Matile, Ph. (1971). Vacuoles, lysosomes of Neurospora. Cytobiologie 3, 324-330.

Matile, Ph. (1975). Lysosomes. In Dynamic Aspects of Plant Ultrastructure, pp. 178-218. Edited by A. W. Robards. London: McGraw-Hill.

NehemiaH, J. L. (1973). Localization of acid phosphatase activity in the basidia of Coprinus micaceus. Journal of Bacteriology rr5, 443-446.

NoRTH, J. \& LEWIS, D. (197I). Phosphatases of Coprinus lagopus: the conditions for their production and the genetics of the alkaline phosphatase. Genetical Research 18, 153-166.

Nyc, J. F. (1967). A repressible acid phosphatase in Neurospora crassa. Biochemical and Biophysical Research Communications 27, 183-188.

PARAG, Y. (1962). Mutations in the $B$ incompatibility factor of Schizophyllum commune. Proceedings of the National Academy of Sciences of the United States of America 48, 743-750.

PrTT, D. (1968). Histochemical demonstration of certain hydrolytic enzymes within cytoplasmic particles of Botrytis cinerea Fr. Journal of General Microbiology 52, 67-75.

Pitt, D. \& Walker, P. J. (1967). Particulate localization of acid phosphatase in fungi. Nature, London $215,783-784$.

RAPER, J. (1966). Genetics of Sexuality in Higher Fungi. New York: Ronald Press.

RAUDASKOSKI, M. (1970). Occurrence of microtubules and microfilaments, and origin of septa in dikaryotic hyphae of Schizophyllum commune. Protoplasma 70, 41 5-422.

RaUdaskoski, M. \& Koltin, Y. (1973). Ultrastructural aspects of a mutant of Schizophyllum commune with continuous nuclear migration. Journal of Bacteriology I16, 981-988.

REISS, J. (1972). Cytologie von Thamnidium elegans Link. I. Cytochemische und phasenkontrastmikroskopische Untersuchungen an Hyphen, Sporangien und Sporangiolen. Protoplasma 74, 71-84.

Scannerini, S., Giunta, C., Panzica, G. C. \& Viglietti, C. (1974). Biochemical and electron microscope evidence for lysosomes in the cultivated field mushroom Psalliota bispora. Journal of Submicroscopic Cytology 6, 132.

SNIDER, P. J. \& RAPER, J. R. (1958). Nuclear migration in the basidiomycete Schizophyllum commune. American Journal of Botany 45, 538-546.

Wessels, J. G. H. (I969). Biochemistry of sexual morphogenesis in Schizophyllum commune: effect of mutations affecting the incompatibility system on cell-wall metabolism. Journal of Bacteriology 98 , 697-704.

Wilson, C. L., Stiers, D. L. \& Smith, G. G. (1970). Fungal lysosomes or spherosomes. Phytopathology 60, $216-227$.

Wilson, R. W. (1972). Acid and alkaline phosphatases in Schizophyllum commune. Canadian Journal of Microbiology 18, 694-695.

ZALOKAR, M. (1960). Cytochemistry of centrifuged hyphae of Neurospora. Experimental Cell Research I9, $114-132$. 